\title{
Long-term follow-up of mitral valve replacement with Starr-Edwards prosthesis
}

\author{
Robert S. Barclay, John M. Reid, John G. Stevenson, Tom M. Welsh, \\ and Norman McSwan \\ From the Cardio-Thoracic Unit, Mearnskirk Hospital, Glasgow
}

A survey is presented of the long-term follow-up of a group of patients who underwent mitral valve replacement with Starr-Edwards prosthesis. The early mortality (up to 3 months from operation) was $40(23.7 \%)$, leaving 128 for follow-up. This ranged from a minimum period of 6 months up to as long as $7 \frac{1}{2}$ years, and 46 have been observed for more than 3 years.

The late deaths numbered $13(10 \%)$, but the clinical status of the remainder (II5) at review in November 1970 was most gratifying. Nine were in grade 0, 77 in grade I, 25 in grade 2a, and only 4 were still seriously disabled. Complications were few, the principal one being thromboembolism which occurred in 24 of the original 168, an incidence of 14.5 per cent, and contributed in part or whole to 9 fatal outcomes. There were no predisposing factors of any significance. With the introduction in early 1968 of the cloth-covered valve, the embolic episodes lessened dramatically (only 3 in the first year after operation, compared with 10 with the older valve during a similar period).

Operation should still be reserved for those with moderate to severe disability. Anticoagulant therapy is still necessary for the first 6 months, but there is mounting evidence to indicate that with the use of the cloth-covered valve it may be possible to discontinue this treatment after 6 months. The main contraindication to operation is pulmonary hypertension at or near systemic level (the systolic pressure in excess of $110 \mathrm{mmHg}$ ).

At present the only effective means of coping with serious mitral regurgitation is by valve replacement. This can be accomplished by various techniques, using valves either manufactured from synthetic material or else fashioned out of living tissue. The synthetic valve currently used most widely is the StarrEdwards (Starr, Herr, and Wood, 1967; Reis et al., 1970; Spencer et al., 1970); other prostheses include the Wadu-Cutter (Hallman et al., 1970), a Dacron velour-covered Teflon disc prosthesis (Beall, 1970), and the University of Cape Town valve (Schrire and Barnard, 1970). The alternative method of using living tissue was embarked upon by Ionescu and his colleagues (1970), a mounted frame being constructed to support an autologous fascia lata graft.

Our experience has been confined exclusively to the Starr-Edwards valve, and the purpose of this communication is to record the long-term follow-up of a group of patients with serious mitral regurgitation who underwent valve replacement with this prosthesis. Received 24 March r97r.
To date there has been a paucity of reports on the late results of mitral valve replacement, and manifestly the analysis of such patients, with particular reference to the causes of late morbidity and mortality and also the functional assessment of the survivors, is of paramount importance (Davies, 1970).

\section{Patients}

During the period June 1963 to July 1970, 168 patients underwent replacement of the mitral valve by Starr-Edwards prosthesis. Patients with either significant aortic or tricuspid valve involvement were excluded from the study. From June 1963 until February 1968, the older type of prosthesis with the bare metal cage (model 6120) was used in 82 patients; but from March 1968, this was superseded by the modified version in which the ball was made of titanium and the metal cage and struts were encased in Teflon (models 6300 and 6310 ) (a total of 86 patients). There were 122 females and 46 males, ranging in age from 17 to 60 years (mean 4I). The systolic pressure in the pulmonary artery measured at cardiac catheterization ranged from 20 to $150 \mathrm{mmHg}$ (mean 55). Atrial fibrillation was present in 126 , and 80 had under- 
gone previous operation by mitral valvotomy on one or in some instances two occasions. There were 40 early deaths, early being defined as any death occurring during operation, immediately thereafter, or within 3 months of operation. This represents a mortality of 23.7 per cent. Thus a total of 128 patients survived this period, and these have been followed for a minimum of 6 months up to $7 \frac{1}{2}$ years.

\section{Results}

There were 13 late deaths, the causes of which are discussed fully later, leaving II 5 patients still alive when reviewed in November 1970. The duration of follow-up is depicted in Table $\mathrm{I}$, from which it can be deduced that 46 have now been observed for more than 3 years since operation. Of the 115,25 were men and 90 were women. Their clinical status was assessed in November 1970 (Table 2), the degree of dyspnoea being graded according to the New York Heart Association. Before operation the majority of patients were in either grades 2 or 3 ; there was a small number of grade 4 (corresponding to orthopnoea at rest). No patient in either grades 0 (normal exercise tolerance) or I (minimal breathlessness on climbing two or more flights of stairs) was submitted to operation. The 2 patients still in grade 3 (Table 2 ) after operation have leaking prosthetic valves; in $\mathrm{I}$ an unsuccessful attempt was made to resuture the valve, while in the second further operation was precluded both by the severity of the pulmonary hypertension and the fact that she had already undergone three previous heart operations. Of the 25 men, 16 were working, 3 were unemployed, and 6 could not return to their previous heavy manual work. The majority of the 90 female patients were able to resume normal housework, with the exception of those in categories of dyspnoea $2 b$ and 3 and several in 2a. Many of the II5 had discontinued diuretic therapy altogether, but a number still required intermittent dosage.

The heart had decreased in size on radiographic examination in more than 50 per cent, but in 40 per cent no alteration had occurred either in the contour or size of the left atrium or ventricle. The majority of these patients, however, had derived considerable benefit with clinical improvement. Finally, I patient had an uneventful pregnancy; with a satisfactory outcome for mother and child (reported separately by (Reid and Barclay, I97I).

Complications There were comparatively few complications in the long-term follow-up, and most of these occurred within the first year after operation. Ball variance was not
TABLE I Duration of follow-up in

II 5 survivors (in years)

\begin{tabular}{llllllll}
\hline$I y r$ & $I-2 y r$ & $2-3 y r$ & $3-4 y r$ & $4-5 y r$ & $5-6 y r$ & $6-7 y r$ & $7-8 y r$ \\
\hline 22 & 24 & 23 & 22 & 12 & 8 & 2 & 2
\end{tabular}

encountered in our series, and haemolytic anaemia did not present any problem. The principal complications are listed below.

Mitral regurgitation Six patients developed a leak in the suture line causing partial detachment of the prosthesis, 2 of whom died very rapidly in severe cardiac failure before further treatment could be instituted. Three were reoperated on, the leak being rectified by reinforcing sutures, but 2 of these died. The presence of pulmonary hypertension at systemic level and the fact that cardiac surgery had been performed on 3 previous occasions precluded any further intervention in the sixth patient.

Bacterial endocarditis This occurred in only one patient within one year of operation, but complete recovery ensued after effective antibiotic therapy.

Bleeding episodes No serious haemorrhage was encountered, but 2 patients had haematuria sufficiently severe to warrant admission to hospital. Investigation was negative, and adjustment of the warfarin dosage quickly abolished the haematuria. Two patients reported solitary episodes of epistaxes, but neither required specific therapy.

Thromboembolism This was by far the principal complication, and occurred in 24 of the original 168 patients (an incidence of $14.5 \%$ ). The sites for lodgement of the embolus were in order of frequency the cerebrum, the kidneys, a peripheral artery, and lastly the spleen. Twenty-one of the thromboembolic episodes were in patients with the older type of valve (model 6120), and to date there have been

TABLE 2 Status of II 5 at follow-up

November 1970

Grade of dyspnoea present

\begin{tabular}{lllrlll} 
Sex & 0 & $I$ & $2 a$ & $2 b$ & 3 & 4 \\
\hline M & 3 & 18 & 3 & 1 & 0 & 0 \\
F & 6 & 59 & 22 & I & 2 & 0
\end{tabular}




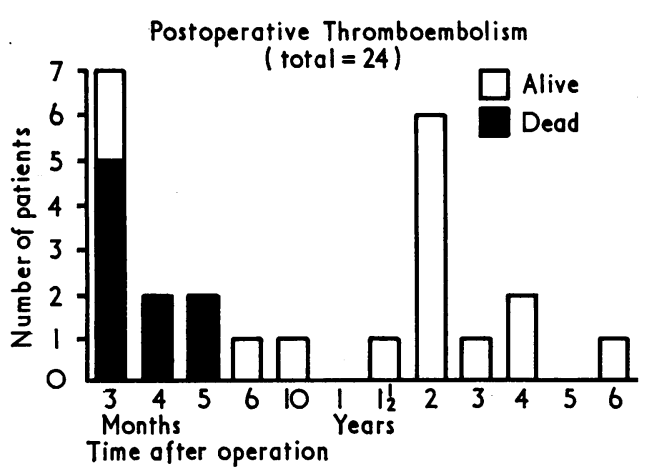

FIG. The histogram shows the interval between the occurrence of thromboembolism and the date of operation.

only 3 with the cloth-covered valve, models 6300 and 6310 (Table 3 ). The accompanying histogram (Fig.) depicts the time interval between operation and the occurrence of the emboli. Anticoagulant therapy had not been previously administered to the patient who sustained an embolus 6 years after operation; warfarin, however, was instituted at this juncture, and the patient recovered fully.

Nine of the patients who sustained emboli died, death being due either solely to the embolus or more commonly to a combination of 'multiple emboli, infection, and concomitant cardiac failure.

Myocardial infarction This occurred in only I patient aged 54 years two years after operation, but full recovery ensued. It seems unlikely that this could in any way be directly attributable to his valve replacement.

Late deaths There were 13 altogether, and several of these have already been discussed. Table 4 lists the aetiological factors involved, and thromboembolism either by itself or combined with infection or cardiac failure accounted for 6 . Four patients died from paravalvar leakage, 2 died at home from unknown causes, and the last death was from pneumonia.

TABLE 3 Incidence of thromboembolism

\begin{tabular}{|c|c|c|}
\hline & Old valve & New valve \\
\hline $\begin{array}{l}\text { No. of patients } \\
\text { Follow-up } \\
\text { Emboli within I year } \\
\text { Emboli beyond I year }\end{array}$ & $\begin{array}{l}82 \\
2 \frac{1}{2}-7 \frac{1}{2} \text { yr } \\
\text { IO } \\
\text { II }\end{array}$ & $\begin{array}{l}86 \\
6 \mathrm{mth}-2 \frac{1}{2} \mathrm{yr} \\
3(p=<0.05) \\
\text { None to date }\end{array}$ \\
\hline
\end{tabular}

TABLE 4 Aetiological factors in 13 late deaths

\begin{tabular}{llllll}
\hline $\begin{array}{l}\text { Leaking } \\
\text { prosthesis }\end{array}$ & $\begin{array}{l}\text { Cerebral } \\
\text { embolism }\end{array}$ & $\begin{array}{l}\text { Cardiac failure } \\
\text { with multiple } \\
\text { emboli }\end{array}$ & $\begin{array}{l}\text { Unknown } \\
\text { (at home) }\end{array}$ & Pneumonia & $\begin{array}{l}\text { Multiple (hepatitis, } \\
\text { emboli, cardiac } \\
\text { failure) }\end{array}$ \\
\hline 4 & 3 & 2 & 2 & I & I \\
\hline
\end{tabular}

\section{Discussion}

Though our early mortality from mitral valve replacement was 23.7 per cent, this figure has declined to below 20 per cent in the last I00 patients. The principal cause of this admittedly high mortality is that all our patients were seriously disabled (either in grade 2, 3, or 4), and our policy, like that of Starr et al. (1967) and Schrire and Barnard (1970), is not to recommend operation in patients with only minimal functional impairment. In the series reported by Starr et al. (1967) the operative mortality was 18 per cent, with a further ro per cent late mortality. The figure for our late deaths was identical, with 13 out of 128 survivors (10\%).

Thromboembolism and paravalvar leakage were the major complications, but neither was as troublesome as in previous series. Detachment of the prosthesis sufficient to produce regurgitation occurred in only 6 of our patients, but it is undoubtedly of very grave significance as 4 of these died. The incidence of embolic episodes was 14.5 per cent (24 out of the original 168 patients). More than half of the emboli occurred within I year of operation; in this period with the new cloth-covered valve there were only 3 compared with Io with the older model. That is statistically significant $(P<0.05)$, but it also emphasizes that anticoagulant therapy cannot be dispensed with altogether even with the new valve. The evidence from our own experience is still not conclusive, but the fact that no thromboembolic episodes were encountered after I year up to a follow-up period of $2 \frac{1}{2}$ years suggests that the first year presents the greatest potential hazard to the patient, and that anticoagulant therapy beyond this period may well be unnecessary in the future when the cloth-covered valve is used.

Starr et al. (1967) reported the strikingly high incidence $(37 \%)$ of thromboembolic complications using the older valve compared with 7 per cent using the cloth-covered one. Spencer et al. (1970) noted emboli in only 4 per cent with the cloth-covered valve prosthesis. All the emboli occurred within 6 months after operation, and they concluded that after this period, when the fibrin covering 
the surface of the cloth had become organized, thrombus formation was then unlikely to take place. The results in the series of Reis et al. (1970) were similar, but both groups advocated that anticoagulant therapy was mandatory for the first 6 months at least, and until further knowledge has been acquired it should be continued beyond this time.

In an attempt to ascertain whether there were any significant factors which might predispose patients to thromboembolism, we analysed certain data in both the embolic group and the series as a whole, but found nothing significant. The mean pulmonary artery pressure of the embolic group was 55 $\mathrm{mmHg}$, while that for the entire group was 54.5. The average age of the embolic group was 44 years, compared with a mean of $4 \mathrm{I}$ years, and finally $16(66 \%)$ were in atrial fibrillation compared with $126(75 \%)$ out of the total of 168 .

The degree of pulmonary hypertension, however, did have a strong correlation not only with early postoperative death but with long-term survival. The systolic pressure in the pulmonary artery in the 13 late deaths averaged $75 \mathrm{mmHg}$, as opposed to a mean of 55 in the entire series. The systolic pressure was in excess of $110 \mathrm{mmHg}$ in 5 of the original 168 patients: all 5 died, 3 within 3 months and 2 within I year of operation. We now consider that pulmonary hypertension of this magnitude is a contraindication to valve replacement.

Many of our female patients are still in the child-bearing age, and naturally the question of contraception is foremost in their minds The association of the 'pill' with venous thrombosis and thromboembolism needs no repetition, and manifestly it would be foolhardy to recommend this means of contraception to patients with valve prostheses. Pregnancy is still the subject of controversy in patients with Starr-Edwards prostheses, as there have been conflicting reports of both success and disaster for both mother and fetus. One of our patients gave birth to a healthy infant 5 years after operation, and there were no complications during the pregnancy or confinement. In principle our advice at present is to avoid pregnancy; in the young nulliparous, however, it may be acceptable to permit one confinement, with the proviso that strict control of anticoagulant therapy is maintained throughout and that a minimum of 2 to 3 years has elapsed since operation. The danger of thromboembolism appears to dwindle substantially after this time.

Spontaneous haemorrhage was infrequent in our experience; only 4 of minor degree were encountered. This is surprisingly low, taking into account the fact that our patients were attending widely scattered centres for their anticoagulant control and that no standard measurement was available. The recent recommendation for the use of a reference standard thromboplastin and the adoption of a uniform system of reporting the one-stage prothrombin time as the British Corrected Ratio (British Medical fournal, I969) should help in future in achieving more uniformity in anticoagulant control. It should go a long way towards the elimination both of bleeding episodes from overdosage and thromboembolism from inadequate dosage of the anticoagulant.

The clinical status of those who survived (II5) is very gratifying. All the patients had been moderately to severely incapacitated before valve replacement, and 9 were now completely symptom free and able to engage in strenuous activities. One of these, a man of 25 years, three years after his operation finished first in a race to the summit of Ben Lomond, a height of 3000 feet. Seventy-seven had minimal dyspnoea (grade I) and could cope with all but the most taxing physical efforts. There were 25 in grade $2 a$, who, while somewhat restricted in their activity, were still improved compared with their previous condition. Four patients were moderately severely incapacitated, 2 due to leaking prostheses and the remaining 2 presumably to myocardial factors attributable either to their underlying rheumatic heart disease, to the operation itself, or to a combination of the two.

One final factor which is virtually impossible to evaluate is the saving in hospital beds resulting from successful heart operations. All the patients who underwent valve replacement would otherwise have remained a burden both to their relatives and the community at large, their grave cardiac disability necessitating increasingly frequent and prolonged spells in hospital. Costly though cardiac surgery with its ancillary service is, it is more than compensated both by the ample saving in hospital accommodation and by the reduction in the consumption of expensive drugs, quite apart from the clinical improvement achieved in the majority of patients.

We wish to express our thanks to all the physicians and cardiologists of the region who referred patients to the Unit for valve replacement and who subsequently provided us with much of the information on the clinical status of the patients as at November 1970 . 


\section{References}

Beall, A. C. (1970). Thromboembolic consideration in mitral valve replacement. (Abstracts, Eleventh International Congress on Diseases of the Chest, Lausanne, Switzerland, Aug. 3-7, 1970.) Bulletin of the American College of Chest Physicians, 9, 15.

British Medical fournal (1969). Editorial. Control of anticoagulants. 4, 125 .

Davies, L. G. (1970). Editorial: Valve replacement. British Heart fournal, 32, 723.

Hallman, G. L., Messmer, B. J., Elkadi, A., Von der Emde, J., and Cooley, D. A. (1970). Clinical experience with the Wada-Cutter cardiac valve prosthesis. Annals of Thoracic Surgery, 10, 9.

Ionescu, M. I., Ross, D. N., Deac, R., Grimshaw, V. A., Taylor, S. H., Whitaker, W., and Wooler, G. H. (1970). Autologous fascia lata for heart valve replacement. Thorax, 25, 46.

Reid, J. M., and Barclay, R. S. (197I). Pregnancy and mitral valve prosthesis. British Medical fournal, $\mathbf{x}$, 326.
Reis, R. L., Glancy, D. L., O’Brien, K., Epstein, S. E., and Morrow, A. G. (1970). Clinical and haemodynamic assessments of fabric-covered StarrEdwards prosthetic valves. Fournal of Thoracic and Cardiovascular Surgery, 59, 84.

Schrire, V., and Barnard, C. N. (1970). Immediate and long-term results of mitral valve replacement with University of Cape Town mitral valve prosthesis. British Heart fournal, 32, 245.

Spencer, F. C., Reed, G. E., Clauss, R. H., Tice, D. A., and Reppert, E. H. (1970). Cloth-covered aortic and mitral valve prostheses. Experiences with II3 patients. Fournal of Thoracic and Cardiovascular Surgery, 59, 92.

Starr, A., Herr, R. H., and Wood, J. A. (1967). Mitral replacement. Review of six years' experience. fournal of Thoracic and Cardiovascular Surgery, 54, 333.

Requests for reprints to Dr. J. M. Reid, CardioThoracic Unit, Mearnskirk Hospital, Newton Mearns, Glasgow. 